\title{
3. EL ARTÍCULO 6 DE LA CONSTITUCIÓN: LOS PARTIDOS POLÍTICOS
}

\author{
ÁNGEL RODRÍGUEZ \\ Profesor Titular de Derecho Constitucional \\ Universidad de Málaga
}




\section{SUMARIO}

INTRODUCCIÓN.-l. LOS PARTIDOS NO EXPRESAN EL PLURALISMO POLÍTICO, SON EXPRESIÓN DEL PLURALISMO POLITICO E INSTRUMENTOS FUNDAMENTALES PARA LA PARTICIPACIÓN POLITICA DE LOS CIUDADANOS.-II. CONCURREN A LA FORMACIÓN, Y NO A LA MANIFESTACIÓN, DE LA VOLUNTAD POPULAR.III. SU CREACIÓN ES LIBRE, DENTRO DE LO ESTABLECIDO EN EL ART. 22.IV. LA REMISIÓN A LA LEY ORGÁNICA DEL CARÁCTER DEMOCRÁTICO DE SU ESTRUCTURA INTERNA Y FUNCIONAMIENTO. 


\title{
3. EL ARTÍCULO 6 DE LA CONSTITUCIÓN: LOS PARTIDOS POLITIICOS
}

\author{
POR \\ ÁNGEL RODRÍGUEZ \\ Profesor Titular de Derecho Constitucional \\ Universidad de Málaga
}

Texto del art. 6 CE:

Texto alternativo:

"Los partidos políticos expresan el pluralismo político, concurren a la formación y manifestación de la voluntad popular y son instrumento fundamental para la participación política. Su creación y el ejercicio de su actividad son libres, dentro del respeto a la Constitución y la Ley. Su estructura interna y su funcionamiento deberán ser democráticos".
"Los partidos políticos, como expresión del pluralismo político, son instrumentos fundamentales para la participación política de los ciudadanos y concurren a la formación de la voluntad popular. Su creación es libre, dentro de lo dispuesto en el artículo 22. Una Ley Orgánica regulará el carácter democrático de su estructura interna y funcionamienton.

\section{INTRODUCCIÓN}

Caben dos grandes maneras de plantearse una reforma constitucional, de nuestra actual Constitución o de cualquier otra. La primera de ellas se sitúa en el mismo plano que el poder constituyente y propone un nuevo sistema político que debe articularse jurídicamente en un texto constitucional alternativo. La segunda se sitúa en un plano diferente, si se quiere técnico-juridico, en cualquier caso subordinado al primero. Esta segunda opción se diferencia sustancialmente de la anterior en que acepta plena- 
mente el sistema constitucional como fórmula política de conjunto, y aborda la reforma como la introducción de nuevos preceptos o la modificación de los ya existentes con la única finalidad de hacer más coherente el sistema en su conjunto, cuya idoneidad no se cuestiona. El objetivo es entonces más limitado: consiste solamente en introducir las reformas estrictamente necesarias para que la interpretación sistemática de la Constitución pueda realizarse sin incoherencias o desajustes excesivos.

La propuesta de las reformas al artículo 6 del texto constitucional que se contienen en este trabajo se plantean desde esta segunda perspectiva. Los cambios que se proponen pretenden que el tenor literal de dicho precepto sea fiel al modelo de constitucionalización de los partidos políticos que se desprende del conjunto de la Constitución. En consecuencia, el punto de partida desde el que se proponen las reformas es, en esos casos, la jurisprudencia del TC en la cual el propio artículo 6 ha sido interpretado, y en virtud de cuyos razonamientos se propone una redacción alternativa del artículo. Se pretende tan sólo que la labor de interpretación sea más fácil y el tenor literal más acorde con ésta. En definitiva, que el propio artículo diga más claramente lo que, según el Tribunal constitucional, dice.

Antes de detallar las reformas que se proponen, es necesario aclarar muy brevemente la postura metodológica de la que se parte. Ello implica precisar tres puntos:

En primer lugar, es necesario destacar la extrema importancia que tiene el artículo 6 de la Constitución como constitucionalización del denominado Estado de Partidos. Sin embargo, es preciso aquí distinguir dos planos: si bien desde el punto de vista político constitucional el precepto comentado explica por sí mismo el realismo constitucional sobre este particular, desde la perspectiva juridico constitucional, el análisis de sus implicaciones exige adentrarse en otros apartados de la Constitución. Porque la peculiaridad del artículo 6 consiste en que su presencia obliga a interpretar de modos diversos otras normas constitucionales, principalmente derechos fundamentales, referentes a los extremos que el texto analizado también regula (el pluralismo, la formación y manifestación de la voluntad popular, la democracia, etc.).

En segundo lugar, es necesario entonces precisar cuál es la naturaleza de esa relación del artículo 6 con otras normas constitucionales. Ésta va más allá de la que es común entre todas las normas de un mismo texto constitucional. Para comprenderla es conveniente concebir el propio artículo 6 como una garantía institucional y entender su relación con otros derechos fundamentales como un caso más de la vis atractiva que las garantías institucionales ejercen sobre los derechos fundamentales. Para- 
lelamente, proponemos entender esos derechos como auténticos derechos públicos subjetivos, que ofrecen su propia resistencia a la tendencia a la institucionalización. Esta tensión entre el derecho y la garantía es la que debe guiar el esfuerzo hermenéutico para llegar a conclusiones válidas acerca de cómo el modelo español de constitucionalización del Estado de partidos influye sobre los derechos de participación (art. $23 \mathrm{CE}$ ) y asociación política (art. $22 \mathrm{CE}$ ).

Por último, conviene aclarar que el objeto garantizado por el artículo 6, el Estado de Partidos, reúne a su vez una doble característica. Con el Estado de Partidos se pretenden elevar a rango constitucional dos realidades diferentes aunque muy relacionadas: el protagonismo de los partidos en la vida pública y su sujeción a los principios constitucionales. Ambos elementos, y el carácter que cada uno de ellos presenta como compensación al otro, deben estar presentes cuando analicemos de qué manera el artículo 6 afecta a diversos enunciados constitucionales.

Hechas estas observaciones preliminares, propongo modificar el artículo 6 de la Constitución de manera que quede claro que los partidos no expresan el pluralismo político, sino que, por el contrario, son expresión de éste; que, ciertamente, concurren a la formación de la voluntad popular, pero no a la manifestación de esa voluntad; que son instrumentos fundamentales para la participación política, pero que de ella son titulares los ciudadanos; y que no están ligados a más respeto de las asociaciones. Por último, propondré añadir al texto del artículo una remisión al legislador Orgánico para que regule la estructura interna y el funcionamiento democrático.

\section{LOS PARTIDOS NO EXPRESAN EL PLURALISMO POLÍTICO, SON EXPRESIÓN DEL PLURALISMO POLITICO E INSTRUMENTOS FUNDAMENTALES PARA LA PARTICIPACIÓN POLITICA DE LOS CIUDADANOS}

Nuestra jurisprudencia constitucional ha destacado en diversas ocasiones la importancia y el significado del art. 6 CE como reconocimiento del protagonismo de los partidos en nuestro sistema constitucional ${ }^{1}$. Cabe

1 Así por ejemplo, y en fecha tan temprana como 1981, el TC afirmó que, en virtud del art. 6, los partidos adquieren "relevancia constitucional», y que ésta "...viene justificada por la importancia decisiva que esas organizaciones tienen en 
afirmar que el protagonismo de los partidos se asegura en este artículo mediante tres atribuciones funcionales, dos de contenido genérico (expresar el pluralismo y ser instrumento fundamental para la participación) y una tercera de contenido específico mediante la que los partidos participan en el sistema representativo (concurre a la formación y manifestación de la voluntad popular). Mi primera propuesta consiste en agrupar las dos atribuciones funcionales de contenido genérico al principio del propio artículo. De esta manera, conseguimos diferenciarlas de la tercera atribución funcional, la propiamente representativa: Podemos justificar este cambio de orden con diversas razones de sistemática:

Realmente los partidos se definen constitucionalmente como expresión del pluralismo y como instrumento fundamental para la participación política, siendo la atribución de funciones en el proceso de formación y manifestación de la voluntad popular una consecuencia de lo anterior y una especificación de cómo esas funciones pueden ejercerse. Una especie dentro de un género; resulta, por lo tanto, más adecuado situar al principio las dos atribuciones genéricas y colocar la específica y propiamente representativa en tercer lugar.

Además, las dos primeras funciones de los partidos, dado su carácter genérico ayudan a comprender la tercera: como veremos, los partidos no pueden ser titulares de la relación de representación (al menos no completamente) puesto que son sólo instrumentos para la participación. $Y$ las normas que impliquen cualquier tipo de privilegio para los partidos deben entenderse siempre en función y en la medida en que realmente expresen el pluralismo.

Creo necesario introducir también algunos cambios en la redacción: según nuestro texto alternativo, los partidos no expresan el pluralismo, sino son expresión de éste; deben definirse, no como instrumento fundamental, sino como instrumentos fundamentales para la participación política, y debe especificarse que ésta - la participación-corresponde a los ciudadanos ${ }^{2}$. Veamos por separado cada uno de estos puntos:

las modernas democracias pluralistas...» (STCE 3/81 fj1). Más extensamente, en la STC 85/86: "La colocación sistemática de este precepto (art. 6) expresa la importancia que se reconoce a los partidos políticos dentro del sistema constitucional, y la protección que de su existencia, y de sus funciones, se hace, no sólo desde la dimensión individual del derecho a constituirlos y a participar activamente en ellos, sino también en función de la existencia del sistema de partidos como base esencial para la actuación del pluralismo político" (fj2). En todo caso, como es sabido, ello no implica que el artículo 6 sea el único artículo de la Constitución que define el régimen constitucional de los partidos (ver más adelante).

2 Mi propuesta de nueva redacción está literalmente tomada de la STC 
En primer lugar, los partidos, más que expresar el pluralismo político, son una expresión de éste. Sustituir la voz activa "expresan" por la pasiva "son expresión" no implica, en este contexto, un cambio de significado, sino de énfasis; mediante esta segunda redacción, el acento se pone en el pluralismo político, no en los partidos. Si tenemos en cuenta que el primero es uno de los valores superiores del ordenamiento (art. 1.1 CE) parece adecuado redactarlo de esta manera: es gracias al pluralismo por lo que existen los partidos, no viceversa. Poner el énfasis en el pluralismo más que en los partidos permite igualmente dos aclaraciones más: en primer lugar, disipar cualquier duda acerca de que los partidos pudieran ser la única expresión del pluralismo (lo que vendría en todo caso imposibilitado, por su carácter de instrumento fundamental, pero no único); y, en segundo lugar permite por ello conservar el calificativo "político", ya que queda de esta manera claro que la Constitución ampara otras manifestaciones del pluralismo político, sin necesidad de amparar las organizaciones no partidistas en expresiones de un pluralismo "social", "económico", etc.

En segundo lugar, parece conveniente sustituir el singular instrumento fundamental por el plural instrumentos fundamentales. De esta manera, no sólo aseguramos una mayor concordancia con el sujeto de la oración que se expresa en plural (los partidos políticos), sino que además se introduce una matización importante: cada partido es un instrumento fundamental para la participación. Poniendo el texto en plural se destaca menos la función centrípeta del sistema de partidos $y$, en esa medida, se corresponde más con el propio pluralismo que se pretende expresar.

Por último, si los partidos son sólo instrumentos para la participación, debe especificarse a quien corresponde la titularidad de ésta. La jurisprudencia del TC ha sido clara al atribuirla a los ciudadanos, aunque sean menos claras las implicaciones que ello conlleva (ver más adelante). Expresándolo así en el propio artículo 6 se asegura su conexión sistemática con el artículo $23 \mathrm{CE}$. De esta manera, además, no queda desequilibrada la mención al artículo 22 que se propone más adelante.

Al referirse en primer lugar a las funciones más genéricas de los partidos, dejando para un tercer lugar la mención a la función propiamente representativa, no sólo se gana en calidad, sino que esta nueva colocación sistemática ayuda a comprender que la función de instrumento fundamental para la participación es más amplia que la representativa. La

$32 / 85$, cuyo fj segundo se refiere a "la consagración constitucional de los partidos políticos como expresión de tal pluralismo (el pluralismo político), cauces para la formación y manifestación de la voluntad popular e instrumentos fundamentales para la participación política de los ciudadanos.." (cursiva mía). 
concurrencia a las elecciones queda así como una de las maneras de la que los partidos pueden cumplir su función de instrumento para la participación ${ }^{3}$. Igualmente, queda claro que la función de instrumento de la participación se supedita a su vez a una expresión efectiva del pluralismo: los partidos, para poder cumplir el resto de las funciones constitucionalmente encomendadas, deben expresar el pluralismo por encima de cierto mínimo (es decir, cumplir una función de agregación de intereses ${ }^{4}$ ), y ello justifica que las leyes impongan barreras de apoyo popular por debajo de las cuales el partido deja de ser un instrumento para la participación ${ }^{5}$.

\section{CONCURRENCIA A LA FORMACIÓN, Y NO A LA MANIFESTACIÓN, DE LA VOLUNTAD POPULAR}

Queda claro que los partidos no son entonces sujetos de la relación representativa sino sólo uno de sus instrumentos, en la medida en que la concurrencia a la formación y manifestación de la voluntad popular es uno

3 En este sentido, la STC 63/87 ha aclarado que también en los institutos de democracia directa "habrán de hacerse presentes, sin duda, los partidos, y, en general, las agrupaciones políticas, más no como titulares del derecho mismo a la participación, sino en lo que a los partidos políticos se refiere, como instrumentos fundamentales que son para hacerla posible" (fj5).

4 Así lo reconoce textualmente la STC 75/85 que afirma que "en su misma razón de ser tienen inscrita tales asociaciones (los partidos políticos) la tarea de ir agregando diversidad de intereses individuales y sectoriales en proyectos y actuaciones de alcance políticon (fj5).

5 De esta manera, encuentran justificación constitucional, por ejemplo, la existencia de barreras mínimas para el reparto electoral de escaños, como aclara la STC 75/85: «...sobre la base de que sean reflejo del esencial principio pluralista, no resulta incongruente con la funcionalidad misma de los partidos exigir, para su acceso a órganos en que también ha de manifestarse la voluntad popular y materializarse la participación, que cumplan por encima de cierto límite esa tarea agregativa" (fj5). Por otra parte, también la existencia de barreras no propiamente electorales definen el papel de los partidos en otros mecanismos de participación, como por ejemplo el referéndum: la STC 63/87 estableció que «carente un grupo político de representación parlamentaria (...) no sólo se descarta, al igual que en el régimen electoral general, su inclusión en la comisión repetida (de control de RTVE), sino también, a diferencia aquí de lo prevenido en la LO 5/85, su mismo acceso a los medios de difusión de titularidad pública" (fj4). Aunque nada dice el TC sobre ello, parece claro que el hecho de que el legislador haya exigido un nivel agregativo mayor a los partidos para acceder a los medios de comunicación de titularidad pública en un referéndum que en unas elecciones desmiente, en principio, la idea de que la participación de éstos es más fundamental en los procesos electorales. Paradójicamente la exigencia es mayor en un instituto de participación directa. 
de los modos de participación política. Su carácter de instrumentos, por lo tanto, ayuda a definir el régimen de la concurrencia a la que se refiere la Constitución. De la jurisprudencia constitucional recaída sobre este punto podemos deducir cuáles son los contornos de la concurrencia a la formación de la voluntad popular, es decir, la concurrencia propiamente electoral; queda, sin embargo, con un perfil mucho más difuso la concurrencia a la manifestación de esa voluntad popular, esto es, el papel del partido en las asambleas representativas. Ciertamente, en ambos momentos es preciso tener en cuenta que el partido no es titular de ninguno de los derechos del art. $23 \mathrm{CE}$, por lo que el partido no puede ser elegido como representante ni puede actuar como tal. No obstante, lo cierto es que el reconocimiento constitucional de las funciones electorales de los partidos es real mente notorio, al contrario de lo que ocurre con su papel en Parlamentos y Ayuntamientos.

De esta manera, la jurisprudencia constitucional ha podido aclara que la función de concurrencia de los partidos en las elecciones les permite un régimen de presentación de candidaturas específico, diferente del que regula las candidaturas no partidarias (cfr. art. 44 LOREG). Esta capacidad les está permitida en virtud de las funciones que la Constitución atribuye a los partidos en tanto tales. Ello define también los límites de este privilegio: la candidatura debe identificarse con el mismo nombre que el partido que la presenta y no con otro; en la medida en que el propio partido no cambie de denominación no podrá presentar candidaturas con un nombre distinto ${ }^{6}$; La indisponibilidad del nombre de la candidatura presenta, sin embargo, alguna excepción: las candidaturas presentadas por coaliciones electorales. Ciertamente, también en ellas la Ley permite, por la misma razón, la inclusión del nombre del partido al que pertenece al lado del nombre de cada candidato (art. 46.7 LOREG). Ahora bien, siguiendo la lógica que apoya esta inclusión, cabría afirmar que en ese caso deberíamos estar igualmente no sólo ante una posibilidad sino ante una obligación: también en las candidaturas de coaliciones presentadas por partidos el nombre de éstos debería ser indisponible ${ }^{7}$. Otro tanto ocurre con las

6 Cfr. STC 69/86: «la legislación electoral otorga a los partidos, en razón de su función constitucional de cauce fundamental para la participación política, la facultad de presentar candidaturas en las que, junto con el nombre de los candidatos, figure la denominación del partido que los propone. Como es claro, este derecho así atribuido a los partidos (...) sólo puede ejercerse por éstos cuando, como tales, comparecen - con su denominación propia, entre otros rasgos- ante el Cuerpo Electoral (...) la identificación (...) como candidatura de presentación partidaria no resulta disponible ni puede alterarse con el simple argumento de que el nombre distinto al en su día registrado resulta también idóneo a juicio de sus promotores" ( $\mathrm{fj} 1)$.

7 No lo ha visto así, sin embargo, la STC 69/86, que destaca como la Ley, aún permitiéndolo, lo que reclama es "la identificación mediante la denominación, 
candidaturas presentadas por Federaciones de partidos, en las que el TC ha admitido la posibilidad de incluir el nombre del partido junto al de cada candidato, pero sin pronunciarse tampoco sobre la necesidad de hacerlo de manera obligatoria ${ }^{8}$.

Por otra parte, gracias al propio artículo 6 y a las disposiciones pertinentes de la Ley Electoral, los partidos ostentan legitimación suficiente para ser parte en diversos procedimientos relacionados con el proceso electoral, incluido el amparo ante el TC, aún no siendo titulares ni activos ni pasivos del derecho de participación política ${ }^{~}$. Esta capacidad, sin embargo, no se extiende a la función representativa de los partidos en las asambleas representativas: en éstas, por el contrario, la legitimidad para recurrir al TC la ostentan tan sólo los representantes, individualmente o en grupo, pero nunca el partido ${ }^{10}$.

siglas y símbolos de los Partidos y de las Federaciones y Coaliciones, y no de modo singular de las formaciones políticas que integren estas últimas" (fj1).

8 Lo que obligó en su momento a una interpretación extensiva del art. 46.7 LOREG, "en el sentido de aplicarlo tanto a coaliciones electorales como a federaciones de partidos", lo que según la STC 168/89, "se adecua a los principios del propio sistema democrático en que los partidos políticos son instrumento privilegiado de participación». Esta interpretación ha sido luego incorporada por el legislador a la propia LOREG tras la reforma de 1991, pero siempre como facultad, no como obligación, por parte de los partidos.

9 La normativa electoral vigente (art. 43 LOREG) soluciona este aspecto mediante la instauración de los representantes de candidaturas, pero el TC ha entendido que, además de esta representación existe al menos un interés legítimo de los partidos en el control de los resultados electorales: junto con la representación que ostentan los representantes de candidatura, la STC 25/90 considera que "si no la titularidad del derecho, sí cabe reconocer a los propios partidos políticos un interés legítimo suficiente a que se respeten las adecuadas condiciones para el ejercicio del derecho al sufragio, atendida su condición de instrumento fundamental para la participación política que les atribuye el art. 6 de la Constitución" (fj3).

10 En dos ocasiones el TC ha hecho una afirmación de este tipo, si bien con algunas matizaciones. En la STC $32 / 85$ deduce del hecho que los partidos no sean titulares del derecho del artículo 23 que éste "(...) lo ostentan sólo las personas físicas o jurídicas, no los grupos políticos carentes de personalidad, como son las fracciones políticas presentes en un órgano colegiado (...) la minoría de uno de tales órganos no puede, en cuanto tal, invocar su infracción" (fj3). Más tarde, la STC $36 / 90$, se enfrenta con un supuesto distinto: aún existiendo estos grupos con personalidad jurídica propia, a diferencia de los Ayuntamientos, en los Parlamentos, ante la impugnación por parte de un partido político con representación parlamentaria de un acuerdo de la Cámara sobre composición de comisiones, el TC afirma que «(...) no sólo no es el partido político recurrente el titular del derecho invocado en amparo, sino que tampoco es quien viene directamente afectado", puesto que la decisión de la Cámara tiene uun alcance estrictamente interno, por su propia naturaleza relativa a la organización del funcionamiento de un Parlamento autonómico» y que, refiriéndose a la relación entre partido y grupo parlamentario, "(...) resulta indudable la relativa disociación conceptual y de la personalidad jurídica e 
Las diferencias de capacidad del partido para actuar en nombre de sus candidatos y en nombre de sus representantes nos introducen en algunos de los problemas que hasta el momento ha encontrado la jurisprudencia constitucional para establecer un régimen unificado para ambos momentos de la relación representativa, puestos que ambos se reclaman del artículo $6 \mathrm{CE}$. Problemas que, a mi juicio, nos permitan afirmar que no se ha reconocido, en realidad una función del partido en cuanto a manifestar la voluntad popular.

El primer aspecto aclarado por la jurisprudencia constitucional sobre este particular fue, como es sabido, que al no poder considerar al partido como representante en el sentido del art. $23 \mathrm{CE}$, no podía reputarse conforme a la Constitución la previsión legal de la antigua Ley de Elecciones Locales sobre la necesidad de abandonar el cargo representativo por expulsión del partido. Así que queda claro que el partido no concurre a la manifestación de la voluntad popular en el sentido de poder exigir la permanencia en sus filas a quien fue elegido en su candidatura para conservar su puesto de representante ${ }^{11}$.

Ciertamente, el TC no ha llevado las conclusiones de esta idea hasta el final: aún reconociendo expresamente que las funciones propiamente electorales de los partidos quedan al margen del diseño elaborado para sus funciones representativas ${ }^{12}$, ha reconocido que los representantes lo son, también, en cierto modo, de sus eleotores ${ }^{13}$, y que la adscripción partidaria de aquéllos no puede quedar exenta de cualquier tipo de relevancia jurídica ${ }^{14}$. Ahora bien, ¿cuál es, en efecto, la relevancia que puede conce-

independencia de voluntades presente entre ambos, de forma que no tienen por que coincidir sus voluntades" ( $\mathrm{fj} 1$ ).

${ }_{11}$ La doctrina de que el art. 23.2 incluye el derecho a permanecer en el cargo sin que éste pueda condicionarse por ser expulsado del partido en cuyas listas se resulta electo se afirma por primera vez en la STC $5 / 83$ y se reitera posteriormente en las SSTC 10/83, 20/83, 28/83, 30/83 y 28/84.

12 Cfr. la STC 36/90, que afirma que "(...) ostentan la titularidad del derecho fundamental comprendido en el art. 23.2 de la Constitución los propios ciudadanos, primero como candidatos a un cargo representativo, y luego como parlamentarios, y en su caso, incluso los Grupos Parlamentarios en que éstos se integran y que ellos mismos constituyen (...) Quedan al margen de este diseño y del ámbito que ahora nos ocupa las funciones que la legislación electoral otorga los partidos políticos» (fj1).

13 Así la STC 32/85, afirma que no puede whacerse abstracción de que los recurrentes son todos ellos, como titulares de cargos electivos, representantes del cuerpo electoral municipal, pero también, aunque en otro sentido, representantes de sus electores, quienes a su través ejercen el derecho de participación en los asuntos públicos que, como derecho fundamental, garantiza el art. 23.1 CE.." (fj3).

14 Para la STC 32/85, las funciones a las que se refiere el art. 6 CE "dotan 
dérsele? Es claro que la adscripción de un representante a un partido no le confiere a éste poder alguno para actuar en su nombre (excepto cuando es tan sólo un candidato) ni puede hipotecar una futura pérdida de su escaño (hasta las próximas elecciones). ¿Entonces?

En algunos casos se ha dejado la puerta abierta a la incidencia del partido en este momento de la relación representativa. Así, por ejemplo, el TC no se ha pronunciado sobre casos de baja voluntaria en un partido, si bien ha sugerido que debe merecer un trato diferente al de la expulsión ${ }^{15}$, o ha usado en la práctica el partido político como criterio de la proporcionalidad en la organización de las asambleas representativas.

Este último punto es, sin duda, el más interesante, pues ahí es donde la jurisprudencia constitucional ha tenido que dar un mayor rodeo para no afirmar directamente el protagonismo de los partidos en la relación representativa. La solución ha sido más fácil en los casos en los que los conflictos planteados se sucedian en sede parlamentaria, en donde la existencia de los grupos parlamentarios exime de conceder a los partidos una relevancia directa. En los casos, por el contrario, sucedidos en los Ayuntamientos, es donde la elusión del protagonismo directo de los partidos ha sido más difícil de conseguir. EI TC ha tenido que acudir a la idea de que ignorar a los partidos supone una quiebra del mandato de proporcionalidad $y$, en ese sentido, una violación de los derechos de todo el cuerpo electoral ${ }^{16}$.

de relevancia jurídica y no sólo política a la adscripción política de los representantes y (...) en consecuencia, esa adscripción no puede ser ignorada..." (fj2).

15 Asi la STC 28/84, en la que el recurrente causó baja voluntaria en su partido, vio innecesario, por otras razones, un análisis sobre la posible inconstitucionalidad del art. 1.7 LEL, pero advierte que, de haber sido necesario para el fallo, hubiera debido tomar en consideración ese dato, "dado que el supuesto de baja voluntaria en el partido no ha sido directamente examinado por este Tribunal en anteriores Sentencias, las cuales se referían a casos de expulsión del partido." (fj3).

16 Según la STC 32/85, "todo órgano representativo ha de reflejar en su composición el resultado de la elección popular. En cuanto que ésta, aunque pronunciándose de modo inmediato sobre personas, se pronuncia también, inmediatamente, sobre los grupos políticos que los proponen como candidatos, la idea de representación política exige (...) lo que la representación de los recurrentes llaman proporcionalidad en la composición de los órganos" (fj2). No obstante este pronunciamiento a favor del partido político como criterio para la distribución proporcional de éstos en los distintos órganos, la STC matiza que ésta "no implica la necesidad de que cada una de las Comisiones sea reproducción exacta, a escala menor, del Pleno Municipal, sino sólo la de que, en cuanto la diferencia cuantitativa y otras consideraciones subjetivas lo hagan posible, al fijar la composición de las Comisiones se procure dotar de presencia en ellas a las fuerzas políticas presentes en el Plenon (ibidem). Y, sobre todo, se cuida de precisar que, en ningún caso, estamos ante violación de derecho alguno de un partido, ya que ula existen- 
En todo caso, lo cierto es que se ha vaciado de contenido la función de los partidos de concurrir a la manifestación de la voluntad popular. Quizá no sea extraño a esta conclusión el hecho de que el análisis jurisprudencial sobre la incidencia de los partidos en el derecho de participación haya venido excesivamente condicionado por el primer caso planteado: en efecto, el Tribunal se plantea en primer lugar la relación de los partidos con el artículo 23.2 CE, en concreto con el derecho a permanecer en los cargos representativos, y sólo en una segunda sentencia retoma el argumento desde el apartado primero del mismo artículo. Es posible que un análisis inicial de la incidencia de los partidos en el derecho activo a participar pudiera haber llevado a conclusiones distintas sobre el apartado segundo del artículo ${ }^{17}$.

\section{SU CREACIÓN ES LIBRE, DENTRO DE LO ESTABLECIDO EN EL ART. 22}

El artículo 6 CE comienza la segunda parte de su articulado, la dedicada a los criterios de constitucionalidad de los partidos, afirmando el principio de libertad en su constitución y actividad y mencionando expre-

cia o inexistencia de las mencionadas infracciones ha de ser apreciada, por tanto, como infracción de los derechos de todos y cada uno de los recurrentes, no del grupo político al que pertenecen" (fj3).

17 En efecto, la primera sentencia sobre el particular, la 5/83, analiza directamente la relación entre el requisito de permanencia en el partido para poder conservar el mandato, del art. 11.7 de la entonces vigente Ley de Elecciones Locales, con el art. 23.2 CE, para concluir que ese requisito vulnera el derecho a permanecer en el cargo público, incluido en el derecho de acceso a las funciones y cargos públicos. Los firmantes del voto particular, disintiendo de la exégesis así realizada del art. $23 \mathrm{CE}$ afirmaron que "tememos que zanje de forma un tanto expeditiva problemas muy delicados relativos a la representación política en las democracias actuales (...) como son los que provocan la incidencia que en el sistema tradicional de la democracia representativa tiene el actual Estado de partidos, el papel de éstos en el funcionamiento de la actual democracia, reconocido expresamente en el art. 6 de nuestra Constitución (...)». quizá por ello, la siguiente ocasión en la que el Tribunal se ve enfrentado con un caso similar, en la STC 10/83, realiza un análisis en profundidad del art. 23.1 CE, afirmando entonces que "el problema nuclear es el de cuál sea el contenido concreto del derecho a participar mediante representantes o, en otros términos, cuáles son, en cuanto hayan de ser tenidas en cuenta para la decisión de este recurso, las notas esenciales del concepto de representación política" (fj2). Los razonamientos que siguen sobre el derecho de participación por medio de representantes son, en esa sentencia, previos a las consideraciones sobre el art. 23.2 CE, pero no se encuentran en la STC 5/83. 
samente dos criterios de constitucionalidad: el respeto a la Constitución y la Ley y la estructura interna y funcionamiento democráticos.

Mi propuesta de reforma para esta parte del artículo comprende los siguientes puntos: en primer lugar, eliminar la mención al "respeto a la Constitución y la Ley" y sustituirlo por una mención directa al artículo $22 \mathrm{CE}$. En segundo lugar, remitir el tema de la organización interna a un desarrollo legislativo. Veamos ahora el primero de estos puntos.

Si bien no existe jurisprudencia constitucional directa sobre el criterio de urespeto a la Constitución y la Ley» al que se refiere este artículo de la Constitución, sí existen indicios suficientes para poder llegar a la conclusión de que esta cláusula no puede añadir nada al deber genérico de acatamiento de la Constitución que se deriva del art. 9.1 CE como consecuencia inmediata de su propia normatividad. Aún admitiendo la existencia de un "deber positivo de acatamiento", más fuerte que el genérico, por parte de los titulares de cargos públicos, suscitaría graves problemas aplicar éste a los partidos ${ }^{18}$. Sin embargo, aún llegando a la conclusión de que pudiéramos aplicar esa obligación a los propios partidos, lo cierto es que ese deber positivo no implica sino un plus difícilmente discernible sobre el deber genérico de acatamiento ${ }^{19}$. Lo cierto es que la cláusula de urespeto» casa mal con el modelo de control de los partidos que instaura nuestra Constitución y que consiste en esencia, como es sabido, en la reducción práctica de los controles al jurídico penal.

18 No conviene olvidar, en este sentido, que los partidos se definen como asociaciones privadas precisamente para dotarles de una mayor garantía. Cfr. la STC 85/86 que afirma que “La Constitución, en su deseo de asegurar el máximo de libertad e independencia sobre los partidos, los somete al régimen privado de las asociaciones, que permite y asegura el menor grado de control y de intervención estatal sobre los mismos." (fj2).

19 El TC se refiere por primera vez a ese deber de "acatamiento positivo" en la STC 101/83, en donde se establece que la sujeción a la Constitución "se traduce en un deber de distinto signo para los ciudadanos y los poderes públicos (..) los titulares de los poderes públicos tienen, además un deber general positivo de realizar sus funciones de acuerdo con la Constitución, es decir, que el acceso al cargo implica un deber positivo de acatamiento entendido como respeto a la misma, lo que no supone necesariamente una adhesión ideológica ni una conformidad a su total contenido (..)». De esta manera, el derecho de participación por medio de representantes del art. $23 \mathrm{CE}$ "no comprende el de participar en los asuntos públicos por medio de representantes que no acaten formalmente la Constitución" (fj2). Ahora bien, excepción hecha de que deba tener una expresión formal, no es fácil hallar otros contenidos de ese acatamiento positivo, ni en esta sentencia ni en otras en donde los términos de la discusión están más cerca del "respeto" empleado por el art. $6 \mathrm{CE}$ (cfr. las consideraciones sobre el deber de "fidelidad" realizadas en la STC 122/83, fj5). En todo caso, ese deber de expresión formal no puede llevarse al extremo de exigir fórmulas ritualistas más allá de la mera expresión de éste (cfr. fj4 de la STC 119/90). 
No a otra conclusión puede llegarse una vez que el TC ha aclarado que el régimen básico de los partidos políticos en lo que hace a los mecanismos de control sobre su creación y actividad viene dado por el art. 22 CE, a cuyas normas el propio art. 6 nada puede añadir que no respete los principios básicos que el art. 22 instaura. Ello implica necesariamente que la mención al respeto a la Constitución quede en una cláusula de estilo o pedagógica que conviene, por lo tanto, eliminar.

En sustitución, propongo afectar directamente el principio de libertad de creación de los partidos a lo dispuesto en el art. 22 CE. En el texto alternativo propuesto se omite así mismo, en este momento, la referencia a la actividad de los partidos, que se remite a la regulación por el legislador orgánico de su funcionamiento. Con ello se consigue diferenciar claramente los controles que el ordenamiento jurídico puede desplegar sobre el momento de creación del partido (control, por lo tanto, preventivo) de los controles ex post sobre su actividad. Aquéllos se remiten directamente a lo dispuesto para el común de las asociaciones por el art. 22 CE. Éstos, tal como los recogiera una LO de desarrollo, podrían desarrollar mecanismos específicos para los partidos, obviamente con los debidos límites constitucionales. De esta manera queda clara la imposibilidad de un control ex ante sobre los partidos políticos distinto del que el art. 22 CE permita para el común de las asociaciones ${ }^{20}$.

Esta nueva redacción ayudaría asimismo a una correcta interpretación del registro que, con carácter genérico para todas las asociaciones,

20 Ya la STC 3/81, la primera que reconoció la importancia del art. 6 CE se refirió también a los propios partidos como "forma particular de asociación", regulado como tal por el art. $22 \mathrm{CE}$, que "no excluye las asociaciones que tengan una finalidad política, ni hay base alguna en él para deducir tal exclusión" (fj1). Aunque, como ha declarado más tarde la STC 67/85, sí existan otras modalidades asociativas que no vienen reguladas por el art. $22 \mathrm{CE}$, que no comprende, por ejemplo, el derecho a "constituir asociaciones cuyo objeto sea el ejercicio de funciones públicas de carácter administrativo relativas a un sector de la vida social". (fj3). De modo que el art. $22 \mathrm{CE}$ "conforma también el núcleo básico del régimen constitucional de los partidos políticosn. Más adelante, el TC ha aclarado la relación entre ambos artículos en el sentido aquí expuesto: el art. $22 \mathrm{CE}$ impide que el art. $6 \mathrm{CE}$ pueda proyectar controles preventivos sobre los partidos. La STC $85 / 86$ afirmó cómo «de la lectura conjunta del art. 6 de la CE en conexión con el art. 22 de la misma, resulta una protección reforzada de la libertad de partidos políticos que debe entenderse afecta no sólo a la actividad de los mismo, sino a su propia creación" (fj2), ya que los requisitos del art. 6 y los del art. 22 CE se sitúan a univeles diferentes" y aquéllos, "en cualquier caso, no repercuten propiamente en el área del derecho a constituirlos, sino que (...) están en función de los cometidos que los partidos están llamados a desempeñar constitucionalmente. La creación de los partidos, no está, pues, sometida constitucionalmente a límites más estrictos que los de las demás asociaciones" (ibidem). 
regula el art. 22.3 CE. Si bien el TC ha aclarado que alguno de los efectos de "mera publicidad" de ese registro pueden tener consecuencias en la práctica previos (la publicidad electoral, por ejemplo ${ }^{21}$ ), la distinción de un régimen de control preventivo, adscrito al 22, y un control posterior sólo para los partidos, que se remite a LO ayudaría a establecer una diferencia radical entre los controles anteriores y posteriores ${ }^{22}$.

\section{LA REMISIÓN A LEY ORGÁNICA DE SU ESTRUCTURA INTERNA Y FUNCIONAMIENTO DEMOCRÁTICOS}

Mientras que en su redacción vigente el art. $6 \mathrm{CE}$, in fine, contiene un mandato, sin más precisión, sobre la estructura interna y funcionamiento democráticos de los partidos, el texto alternativo que se propone remite el tema a una Ley Orgánica que deberá regular estos extremos.

Se parte, para ello, de una previa consideración sobre la no idoneidad, tampoco en este punto, de la Ley 54/78, la actual ley de desarrollo. No sólo, como se ha dicho, la ley actual contiene mecanismos preventivos de control difícilmente conciliables con la Constitución, sino que, en lo que hace al mandato constitucional de organización interna democrática resulta claramente insuficiente.

Ha sido sin duda la propia ilegitimidad constitucional de la ley, criti-

21 Cfr. la STC 21/83 que condiciona el requisito de la inscripción registral para la presentación de candidaturas, si bien especificando que la Ley (entonces el RDL 20/77 de Normas Electorales), al exigir el requisito de la inscripción «no está regulando ni el derecho de asociación ni el momento en que cada asociación política adquiere personalidad jurídica, sino que se limita a establecer, dentro de la ordenación del proceso electoral que constituye su objeto, la exigencia de un requisito razonable dentro de la publicidad que debe caracterizar la concurrencia y el desarrollo de cada contienda electoral", requisito que no puede tacharse de inconstitucional, "pues el art. 22.3 CE exige que las asociaciones constituidas a su amparo deberán inscribirse en un registro a los solos efectos de publicidad" (fj2). El mismo requisito se contiene actualmente en el art. 44.1.a) de la LOREG.

22 Un problema distinto, que excede de las intenciones de este trabajo, viene dado por la interpretación adecuada que debe darse al art. 22 y los controles previos que éste puede permitir. Hay que destacar, en este sentido, que la más que probable inconstitucionalidad de la Ley $54 / 78$ en todo lo que signifique instaurar un control previo específico para los partidos, ha logrado, no obstante, no ser declarada todavía por el TC, que, ciertamente, ha tenido alguna oportunidad para hacerlo. Cfr. STC 85/86, sobre todo fj3. 
cada duramente, aunque no derogada, por el TC ${ }^{23}$, la que ha impedido una aplicación extensiva de la Ley en cuanto al control sobre el carácter democrático de la estructura interna de los partidos.

La Ley deberá permitir un control judicial (por supuesto que ex post) tanto sobre la organización estatutaria como del funcionamiento efectivo del partido. La inclusión del funcionamiento, eliminado del art. 6 la mención al respeto a la Constitución, no debe suscitar dudas respecto a la posibilidad de legitimar un control que vaya más allá de la democraticidad interna efectiva del partido ${ }^{24}$, y debería aclarar la confusa doctrina constitucional actual sobre la posibilidad de incluir el derecho a participar en el interior de un partido político entre los contenidos del derecho de participar en los asuntos públicos del art. 23 CE. Sólo de esta manera se podrá reequilibrar el protagonismo concedido a los partidos en el sistema constitucional con un control efectivo sobre el carácter democrático de su interior ${ }^{25}$.

23 La STC 85/86 dice de ella, con razón, que es «más tributaria de su inmediato antecedente legislativo que de la regulación constitucional al respecto" (fj3).

24 Por lo demás, la posibilidad de un control no sólo sobre la estructura estatutaria, sino también sobre el funcionamiento efectivo, quedó abierta ya con la STC 3/81 que aludió al control judicial como "el medio con que cuenta el Estado para su defensa en el caso de que sea atacado por medio de un partido que, por el contenido de sus estatutos o por su actuación al margen de éstos, atente contra su seguridad" (fj9, cursiva mía). En todo caso, este funcionamiento exigiría interpretar las "actividades contrarias a los principios democráticos" del art. 5.2.b de la actual Ley bien como funcionamiento interno (o sea, despliegue efectivo de sus normas estatutarias) o actividades claramente delictivas.

25 La jurisprudencia constitucional sobre la posibilidad de controlar en esa sede la concordancia con principios democráticos del funcionamiento interno, enjuiciando, por ejemplo, el acto de expulsión del partido, está llena de pronunciamientos ambiguos y de obiter dicta de difícil proyección para el futuro. Ciertamente, la STC 10/83 se negó a enjuiciar la corrección estatutaria de un acto de expulsión sobre los argumentos de que los actos de un partido político no son actos de un poder público $y$, además, no habian sido examinados previamente por la jurisdicción ordinaria (fj1). Posteriormente, sin embargo, el razonamiento del TC se ha centrado casi exclusivamente en el segundo de estos argumentos. Así, la STC 5/83, por ejemplo, no llega a pronunciarse sobre el particular, puesto que el recurrente no reproduce esa queja en su escrito de alegaciones, al contrario de lo que habia hecho en la presentación del recurso (cfr. STC 5/83, fj2). La STC 30/83, por su parte, reconduce otro caso de expulsión a un análisis exclusivo de sus consecuencias según la ley electoral, renunciando a analizar si el acto constituye una vulneración autónoma del derecho de asociación "aunque no sea más que por la buena razón de que los propios demandantes afirman haber deducido demanda ante la jurisdicción ordinaria (...) por lo que hay que concluir que en modo alguno se ha agotado la vía judicial previa", lo que exime asimismo de confrontar con el art. $22 \mathrm{CE}$, sino sólo con el $23 \mathrm{CE}$, el acuerdo por el cual, al ser expulsados, pierden el cargo representativo (fj2). En la STC 71/84 (enjuiciando la expulsión del actor no de un partido, 
sino de una organización empresarial (...) debido a su afiliación a un partido), el Tribunal, al haber interpuesto el recurrente recurso de amparo contra una resolución judicial que entendió que no había habido ilícito penal en el modo de producirse la expulsión, denegó el amparo puesto que el propio recurrente, al haber elegido la vía penal en la jurisdicción ordinaria, había acotado él mismo los términos de su defensa, y ello a pesar de criticar que el juez a quo se hubiera extendido más allá del razonamiento sobre la inexistencia del delito alegado, "formulando afirmaciones sobre la no vulneración (por el acuerdo de expulsión del art. 22.1 CE que esta Sala no puede sino calificar de improcedentes ni desde luego hacer suyas sin más. Pero esta consideración crítica no puede llevarnos más allá de esta reserva" (fj4). Por último, la STC 23/84 parece indicar, a sensu contrario, que la relevancia constitucional de los partidos, a diferencia de los Colegios Profesionales, permitiria incluir el derecho a participar en su interior dentro del art. 23 CE (cfr. STC 23/84, fj4). En todo caso, esa posibilidad exigiría una nueva forma de acercarse al problema de la presencia de los partidos en la relación de representación (cfr. supra, nota 18), pues como bien razona la STC 28/83, dentro del actual estado de cosas, poco importaría que el acto de expulsión estuviera de acuerdo con la Ley o no, ya que nunca podria tener repercusiones sobre los cargos representativos (fj4). Es posible que una acertada inclusión del partido en la relación representativa hubiera levantado menos suspicacias si se hubiera aclarado desde el principio que, como compensación, ello hubiera exigido elevar al rango de derecho fundamental protegido por el art. 23 CE la participación en su interior. 